\title{
ENTREVISTA
}

\section{POSCONFLICTO, PAZ Y EDUCACIÓN: ENTREVISTA A HÉCTOR ESPINOSA OLIVER, VICEMINISTRO DEL INTERIOR PARA LAS RELACIONES POLÍTICAS DE COLOMBIA}

\section{Post-conflict, peace and education: Interview with Héctor} Espinosa Oliver, Vice minister of the Interior for Political Relations of Colombia

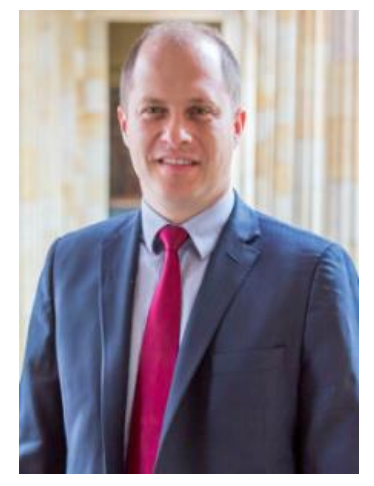

\section{Luis Fernando Redondo 1 Bernardo Romero Torres ${ }^{1}$}

Foto: Ministerio del Interior

Héctor Espinosa Oliver, viceministro del Interior para las Relaciones Políticas de Colombia

Cómo citar:

Redondo, L. y Romero, B. (2018). Posconflicto, paz y educación: Entrevista a Héctor Espinosa Oliver, viceministro del Interior para las Relaciones Políticas de Colombia. Revista de Jóvenes Investigadores Ad Valorem, Vol. 2(2), 66-

\footnotetext{
* Entrevista realizada en 30 de noviembre de 2017

${ }^{1}$ Estudiantes del Programa de Economía de la Universidad de Cartagena
} 
Antes de su posesión en el cargo actual reiteró su compromiso con las iniciativas que implementen los acuerdos de paz con las Farc, en ese sentido. ¿Cómo entiende usted el posconflicto?

El haber conquistado el derecho de resolver nuestros conflictos por las vías de la civilidad es el mayor logro y lo que debemos siempre destacar.

Ahora el reto es convertir ese logro en un motor de desarrollo para todos los colombianos, ese debe ser el objetivo de todos en este periodo histórico que ya comenzamos a implementar. Es lo que se ha llamado posconflicto, que incluso muchos han llamado posverdad.

Pero más allá de los nombres que le demos a este período, que seguramente serán los historiadores quienes mejor lo califiquen, lo que realmente debemos pensar es en la actitud que tomemos durante este momento crucial del país. Y en mi concepto, lo que se debe lograr ahora es superar el rechazo y el pesimismo que en muchos sectores de la sociedad hay.

Urge convencer a la población de las posibilidades que ahora tenemos como nación pacífica y próspera. Hoy es mucho lo que está en juego para todos nosotros. Hay riesgos por asumir, pero está en juego la confianza en el Estado que es la base de su legitimidad. No se trata solamente de crear más normas o nuevos escenarios legales, se trata de regular nuestras relaciones sociales, de trabajar en principios, en que nuestra sociedad mejore sus estándares éticos. Debemos aprovechar este momento para que seamos una sociedad pacífica, transparente e incluyente.

La paz llevará a mejores resultados en materia social y económica para Colombia. ¿De qué manera reduciría la pobreza y la desigualdad en las zonas más afectadas por el conflicto armado?

Quien fuera Alto Comisionado para la Paz, Sergio Jaramillo, empleaba una frase bastante directa que refleja mucho de lo que considero debe lograrse en el país. Él decía recurrentemente que: "Necesitamos romper los ciclos históricos de violencia". Y en eso, en mi opinión, la inclusión social tendrá un rol determinante.

Creo que de la inclusión dependen en buena parte la seguridad y la confianza. Debemos ser capaces de construir una sociedad donde todos quepamos. Donde quepan nuestros pensamientos y nuestras visiones.

Y hablo de la inclusión entendida no solo como el acceso material a bienes y servicios, sino también a espacios de deliberación social, de cultura, de deporte, de formación, de recreación, de escucha y de acompañamiento. De garantías de no discriminación y de aislamiento. 
Considero que la exclusión social termina generando unas vulnerabilidades en la sociedad y de manera muy especial en los jóvenes. Algunas de ellas, la captura de mercados ilegales y el consumo de sustancias psicoactivas, que terminan sin duda generando contextos sociales frágiles y proclives a la criminalidad. Y esa falta de opciones, se ve reflejado en situaciones de pobreza y aislamiento social, en donde la inequidad siempre afectará a los más vulnerables. Estoy seguro que la inclusión de la que hablo, permitirá superar esa desigualdad.

\section{¿Para usted qué papel juega la educación, en todos sus niveles, en el proceso de reconciliación después del conflicto?}

La educación lo es todo. Abre puertas, acerca mundos, permite compartir experiencias nuevas, brinda aprendizaje y ofrece alternativas para interactuar con personas de todo nivel y capacidades.

La educación nos permite distinguir procesos, reconocer errores, aprender desde la experiencia. Con la educación se logra inclusión, equidad, transparencia. Fortaleciendo la educación se abren oportunidades, se logra desarrollo y se construyen caminos de progreso para cada individuo.

Es por medio de la inversión e implementación de políticas de educación que podemos trabajar en temas como la prevención y mitigación de daño del consumo de sustancias sicoactivas. Con la educación desarrollamos planes de inclusión social, con la educación podremos atacar las causas de los problemas y garantizar un impacto positivo en todos nuestros indicadores.

\section{La Universidad de Cartagena ha implementado una estrategia de llevar educación de calidad a zonas afectadas por el conflicto armado (Los Montes de María) con presencia de programas académicos de ciencias económicas e ingeniería. ¿Cómo considera usted que el gobierno central podría acompañar o fortalecer estas iniciativas?}

Una educación para todos, gratuita, de calidad, es la base del progreso, el mayor motor de movilidad social y abre las puertas de las oportunidades para los colombianos. Es además la mejor semilla para reconciliación, y la mejor forma de apoyar las iniciativas de la academia, es fortaleciendo los presupuestos de inversión en la educación.

Este gobierno, en sus siete años y cuatro meses de gestión ha invertido 212 billones de pesos para fortalecer la educación. Casi el doble de lo que recibe cada año el gobierno nacional por impuestos.

Lo que el Estado ha hecho es importante destacarlo. Con el programa Colombia Bilingüe, 950 profesores extranjeros han llegado al país para formar a 3.700 maestros en lenguas. El ICETEX ha 
concedido créditos a 411 mil jóvenes para que hagan sus estudios de pregrado y posgrado en el país y en el exterior. El programa 'Ser Pilo Paga' cuenta con más de 30.500 pilos de los estratos más bajos estudiando en las mejores universidades.

Aunque las cifras de inversión son multimillonarias, sabemos que para lograr estándares internacionales en calidad debemos invertir mucho más y hacer más proyectos e iniciativas que mejoren nuestra educación.

\section{Si bien es cierto que la tasa de criminalidad está en sus niveles más bajos actualmente, la inseguridad en las principales ciudades ha aumentado de manera significativa. ¿A que debe usted este fenómeno?}

La inexistencia de espacios e incentivos para la cultura, la recreación y utilización de tiempo libre, en una sociedad traumada por el conflicto, por la pobreza, la violencia intrafamiliar, y cada vez más vulnerable al consumo de sustancias, ha conducido a un crecimiento exponencial de la inseguridad en las ciudades.

Creo que existe una correlación entre la exclusión social, el consumo de sustancias psicoactivas (PSA) y la problemática de seguridad ciudadana. Lo cual nos lleva a plantear que el enfoque de la política en el control de la oferta de sustancias psicoactivas es insuficiente, y necesitamos concentrar más esfuerzos en el control de la demanda de sustancias.

La angustia de los padres de familia por que sus hijos no caigan atrapados en el consumo y el pandillismo, en redes de mercados ilegales, así como la frustración de ver que el Estado y la sociedad no generan las condiciones para ayudarles a evitarlo, es un tema que no admite dilación y reclama con urgencia una intervención integral por parte del Estado.

En Colombia hemos gastado muchos años y recursos en pretender controlar problemas de seguridad, que afectan, entre otras, la integridad y tranquilidad del ciudadano, con políticas punitivas y represivas que no han arrojado los resultados esperados.

La manera tradicional de combatir la delincuencia, es decir, la policiva, represiva o punitiva; tiene consecuencias graves desde el punto de vista de la familia, de la comunidad, de la administración de justicia y el desarrollo de la política criminal. Este enfoque por sí solo no es suficiente. Se necesita impulsar y fortalecer la Política de Reducción del Consumo de Sustancias Psicoactivas y su impacto en materia de seguridad. Invertir en inclusión, escucha, orientación, capacitación y acompañamiento resulta siendo más eficiente. 